\title{
Structural Befavior of Reinforced Concrete Shell with Stiffener under Pressure
}

\author{
Takashi Hara
}

\begin{abstract}
Reinforced concrete cylindrical shell with edge beam on meridional free edges was analyzed by use of FEM. As the edge beam on meridional edge, three kinds of rectangular beams were arranged. One was connected to the shell at the gravity center of the beam and the others were connected at the bottom or the top of the beam. The model was supported at four corner of $\mathrm{R} / \mathrm{C}$ shell. Applied load was the external pressure. From the numerical analyses, the shell connected with the top of the beam showed the smooth deformation and the stress distributions as well as the highest load carrying capacity.
\end{abstract}

Keywords-FEM, RC shell, beam arrangement, stiffening, cutting edge, deformation, crack

\section{Introduction}

Reinforced Concrete (R/C) shell has been used to construct a large gymnasium and a storage tank as well as a tunnel underground or in the water. Figure 1 shows the underground indoor gymnasium at Osaka, Japan. RC shell is originally a continuous structure and shows the large load bearing capacity under an external pressure. However, to apply these structures to such purpose, the shell structure is cut at any particular portion and loses their continuum characteristics. Therefore, as the stresses concentrate around the cutting edges and the opening spaces, edge beams must be placed to avoid the stress concentration and a local failure.

IASS recommendation [1] and ACI building code [2] recommend to place edge beam at free edges and the intersection of shells. However, the required dimension and the details of connection method between shell and edge beam are not clearly recommended.

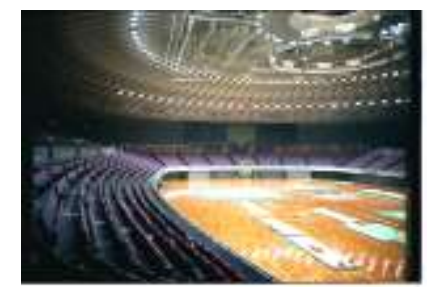

Figure 1. Osaka Central Gymnagium

In this paper, $\mathrm{R} / \mathrm{C}$ cylindrical shell with edge beam on meridional free edges was analyzed by use of FEM. R/C shell had 960x960 mm plan and the thickness was $10 \mathrm{~mm}$. The radius and the depth of the shell were $688 \mathrm{~mm}$ and $190 \mathrm{~mm}$, respectively. R/C shell was supported only at the four corners and was subjected to the external pressure in radial direction.
As the edge beam, three kinds of rectangular beams, which had $2 \mathrm{~cm}$ width and $4 \mathrm{~cm}$ depth, were arranged. One was connected to the shell at the gravity center of the beam and the others were connected at the bottom or the top of the beam. In the numerical analyses, the deformation and the stress distribution as well as cracks of the shell mentioned above were analyzed precisely.

\section{Numerical Model}

\section{A. Model Geometry}

Figure 2 shows R/C shell model [3]. The width and length of cylindrical shell are $960 \mathrm{~mm}$ and $960 \mathrm{~mm}$, respectively. The thickness of the shell is $10 \mathrm{~mm}$. Radius of the cylinder is $688 \mathrm{~mm}$. In the middle of the thickness of the shell, reinforcement mesh (diameter $0.75 \mathrm{~mm}$ ) with $5 \mathrm{~mm}$ openings is arranged. On both the meridional edges, edge beams, which are $20 \mathrm{~mm}$ width and $40 \mathrm{~mm}$ depth, are attached. R/C shell is thin and light weight but an edge beam is heavy comparing an $\mathrm{R} / \mathrm{C}$ shell. Referred to the previous paper [3] The beam size was defined as the size that shows the minimum ratio of the ultimate strength to its weight.

The stiffened $\mathrm{R} / \mathrm{C}$ shell is supported at four corners as shown in Figure 3.

Considering the effects of the connecting method between $\mathrm{R} / \mathrm{C}$ shell and edge beam, three kinds of arrangements of the edge beam were considered. Figure 4 shows the arrangement of the edge beam.

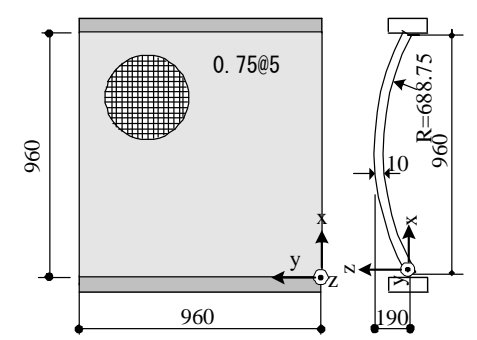

Figure 2. Geometric dimensions of R/C cylindrical shell (mm)

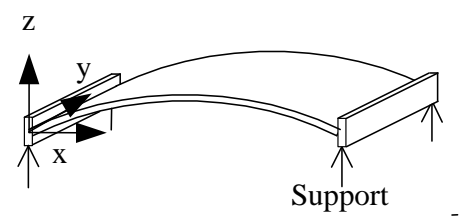

Figure 3. Supporting of R/C cylindrical shell 
"no rib" shows R/C shell without edge beam. In C-type, the gravity center of the edge beam is connected to $\mathrm{R} / \mathrm{C}$ cylindrical shell. In L-type, the top of the edge beam is connected to $\mathrm{R} / \mathrm{C}$ cylindrical shell and the main body of the edge beam is under $\mathrm{R} / \mathrm{C}$ shell. On the other hand, in U-type, the bottom of the edge beam is connected to $\mathrm{R} / \mathrm{C}$ cylindrical shell.

Two $\phi 3 \mathrm{~mm}$ reinforcements were arranged on both top and bottom parts of the edge beam. The cover of the micro concrete was $5 \mathrm{~mm}$. The reinforcements of the shell were extended to the edge beam and were used for the shear reinforcement of the edge beams.

(a) No rib

(b) C-type

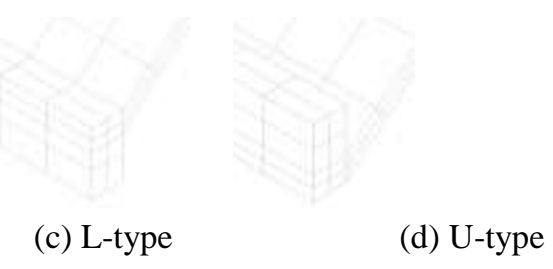

Figure 4. Beam connection method

TABLE I. MATERIAL PROPERTIES OF CONCRETE AND STEEL

\begin{tabular}{|lc|}
\hline \multicolumn{2}{|c|}{ Concrete } \\
\hline Compressive Strength (MPa) & 38.2 \\
Tensile Strength(MPa) & 3.8 \\
Young's Modulus(GPa) & 23.6 \\
Poisson's Ratio & 0.20 \\
\hline \multicolumn{2}{|c|}{ Steel } \\
\hline Yield Stress(MPa) & 235 \\
\hline Tensile Stress(MPa) & 449 \\
\hline Young's Modulus(GPa) & 206 \\
\hline Tangential Modulus(GPa) & 21 \\
\hline
\end{tabular}

\section{B. Material Properties}

The model was assumed to construct by the mild steel and the micro concrete. Both the material parameters are shown in Table I. Material properties were obtained by the material tests.

\section{Numerical Model}

Figure 5 shows the numerical models. C-type denotes the model with edge beams connected at the gravity center. L-type and U-type show the model with edge beams connected at the beam top and the beam bottom, respectively (see Figure 4). In each model, R/C cylindrical shell and edge beams were divided into solid elements with 20 nodes.

The inelastic behavior of concrete possesses the recoverable strain components and irrecoverable strain components. Under tri-axial stress state, the yield function depends not only on the mean normal stress $I_{l}$ but also on the second deviatoric stress invariant $J_{2}[4,5]$. The yield condition of tri-axial compressive concrete is expressed by Drucker Prager criterion [4-7].

$$
f\left(I_{1}, J_{2}\right)=\sqrt{\beta\left(3 J_{2}\right)+\alpha I_{1}}=\sigma_{0}
$$

where $\alpha$ and $\beta$ are the constants. Also $\sigma_{0}$ is the equivalent stress. Parameters adopted in the criterion are defined by the Kupfer's experiment [8]. It is assumed that the initial yield begins when the equivalent stress exceeds $0.3 f_{c}\left(f_{c}\right.$ : compressive strength of concrete) [4]. Also, the crushing condition of concrete is described as a strain control phenomenon and the crushing condition is defined as like as the yield function [4].

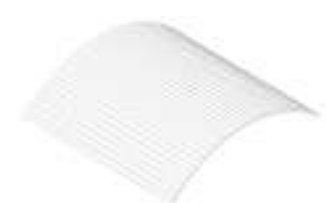

(a)No rib

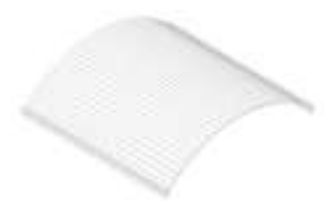

(c)L-type

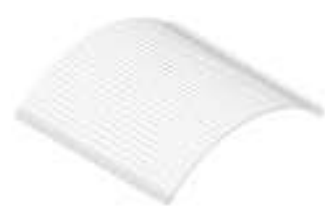

(b) C-type

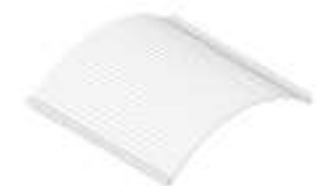

(d) U-type
Figure 5. Numerical model

The response of concrete in tension is modeled as a linear-elastic brittle material and maximum tensile stress criteria are employed. After cracking, to evaluate the stiffening of reinforced concrete, the stress reduction of the concrete normal to the cracked plane is assumed as an exponential degradation curve [5].

$$
\begin{aligned}
& \sigma=f_{t}^{\prime} \exp \left(-\frac{\varepsilon-\varepsilon t^{\prime}}{\gamma}\right) \\
& \gamma=\frac{G_{f}-0.5 f_{t}^{\prime} \varepsilon c r l c}{f_{t} \ell_{c}}
\end{aligned}
$$

where $f_{t}$ ' is maximum tensile strength of concrete, $\gamma$ is the tension stiffing parameter, $\varepsilon_{t}{ }^{\prime}$ is crack strain, $G_{f}$ is the fracture energy of concrete, $l_{c}$ is the cubic root of volume in Gaussian point and $\varepsilon_{c r}$ is the strain in crack [5]. $\gamma=0.1$ is adopted in this paper due to the characteristics of normal concrete.

The reinforcing bars are considered as steel sheet. The bilinear idealization is adopted in order to model the elastoplastic stress strain relationship and both the tensile and the compressive states are governed by the same relationship [5].

\section{Numerical Results}

Figure 6 shows the load - displacement relation for each connecting method between edge beam and R/C shell. The 
loading condition is the external pressure in radial direction. Applied load is on the shell surface and in its radial direction. The ordinate denotes the pressure $\left(\mathrm{N} / \mathrm{mm}^{2}\right)$. The abscissa shows the displacement at the shell top in the middle of R/C shell. The legend "no rib" means the numerical result of $\mathrm{R} / \mathrm{C}$ shell without edge beams.

The edge beam improves 0.1 to 3 times the load carrying capacity of $\mathrm{R} / \mathrm{C}$ shell without edge beam. In case $\mathrm{R} / \mathrm{C}$ shell without edge beam deformed upward in the initial stage and the deformation turned to downward. U-type connection shows the largest stiffness but small improvement till failure. $\mathrm{R} / \mathrm{C}$ shell with $\mathrm{C}$-type beams shows larger stiffness than that of $\mathrm{L}$ type. $\mathrm{R} / \mathrm{C}$ shell with L-type shows smaller stiffness than that of Type U. However, the ultimate strength of $\mathrm{R} / \mathrm{C}$ shell with Type $\mathrm{L}$ shows the largest ultimate strength.

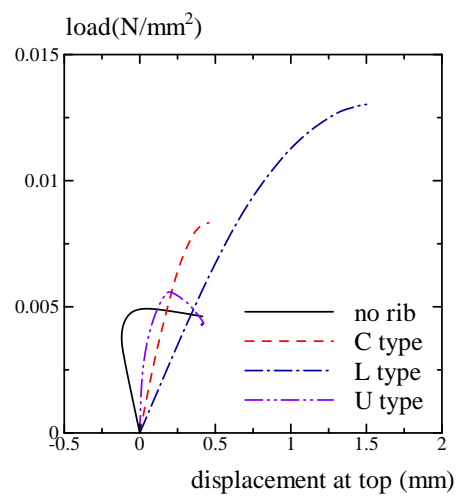

Figure 6. Load-displacement relation

Figure7 shows the comparison of the load deflection behavior of R/C shell with various type of edge beam under vertical external pressure, i.e. under gravity load [9]. In case of "no rib", R/C shell deforms only in downward direction.

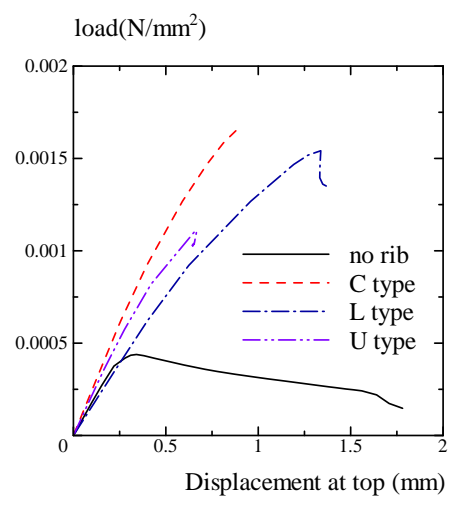

Figure 7. Load-displacement relation under vertical pressure [9]

C-type shows larger load carrying capacity than that of the shell with L-type. However, the difference of the ultimate strength of both type was small. Also, C-type shows the brittle failure but R/C shell with L-type beams shows ductile failure. Therefore, L-type is suitable for the edge beam.

Consequently, L-type connection of edge beam was suitable under both external radial and gravity pressure.
Figure 8 shows the deformation and crack patterns of $\mathrm{R} / \mathrm{C}$ shell without edge beam. Deformation shows like a beam bending analogy. The cracks concentrate at four corners and meridional edges. The large number of cracks appears in the middle of the meridional edges and the ends of hoop direction. The failure begins at corners. R/C shell could not show large ultimate strength due to such failure.

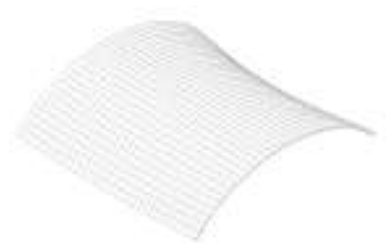

(a) deformation

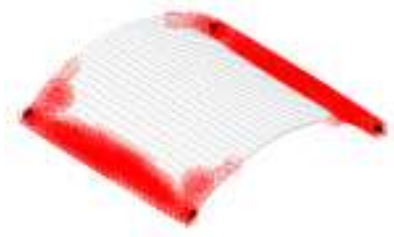

(b) cracks

Figure 8. Deformation and cracks of R/C shell without edge beam

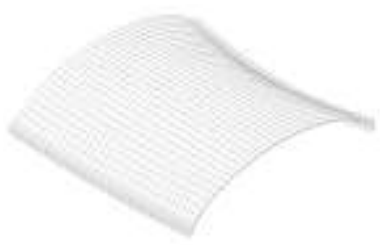

(a) deformation

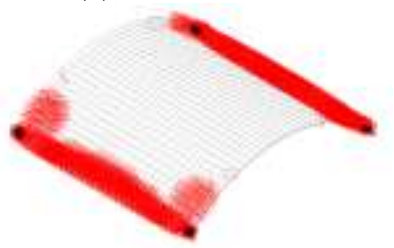

(b) cracks

Figure 9. Deformation and cracks of R/C shell with C-type edge beam

Figure 9-11 shows the deformation and crack patterns of $\mathrm{R} / \mathrm{C}$ shell with C-type, L-type and U-type beam connections, respectively (see Figure 4).

In Figure 9 (C-type), the deformation pattern is the same as "no rib" but the magnitude was different. The deflection of the meridional edges was small. The crack pattern was also the same as that of "no rib". However, the cracks around the ends of hoop edges were reduced. Also, the cracks on the meridional edges were reduced due to the effect of the edge beam..

Figure 10 (L-type) represented the numerical results of $\mathrm{R} / \mathrm{C}$ shell with L-type edge beams. The top of the beam was connected to the upper surface of $\mathrm{R} / \mathrm{C}$ shell. The deformation patterns represented flat shape and the whole surface of $\mathrm{R} / \mathrm{C}$ shell resisted against the external pressure. The cracks distributed around both meridional and hoop edges. 
The beams placed on the meridional edges worked to transfer the out of plane bending moments. Also, the hoop edge of R/C shell transfer the compressive force as well.

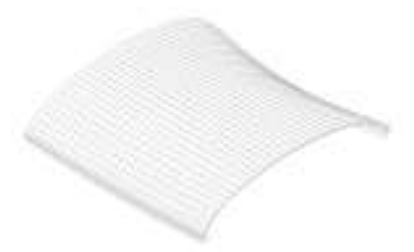

(a) deformation

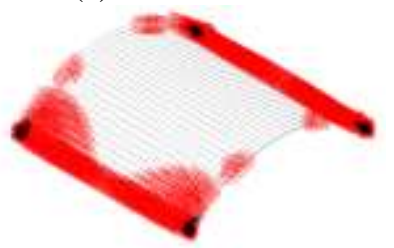

(b) cracks

Figure 10. Deformation and cracks of R/C shell with L-type edge beam

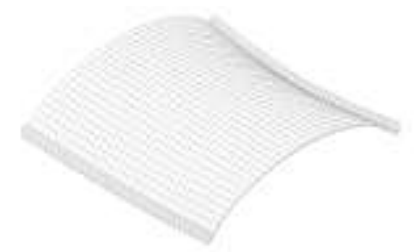

(a) deformation

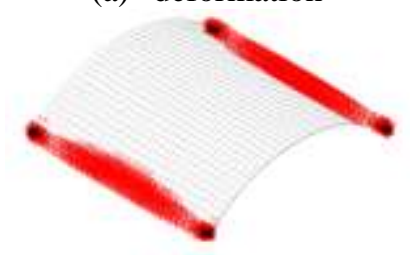

(b) cracks

Figure 11. Deformation and cracks of R/C shell with U-type edge beam

In Figure 11 (U-type), the deformation of R/C shell represented as the same as that for C-type beams. The deformation of the edge beam of U-type shows the larger deformation than that of L-type. There was no cracks on the hoop edge and the cracks concentrated around the meridional edges. Cracks initiated on the edge beam and propagated to the $\mathrm{R} / \mathrm{C}$ shell element. The number of craks increted in the middle of the edge beam.

From the nimerical results, Crack patterns of R/C shell with "no rib" and C-type showed the same crack distribution. Cracks of $\mathrm{R} / \mathrm{C}$ shell with L-type beam spreaded in $\mathrm{R} / \mathrm{C}$ surface and the stress redistribution srised and the stress transfer were detected.

\section{Iv. Conclusions}

In this paper, $\mathrm{R} / \mathrm{C}$ cylindrical shell with edge beam on meridional free edges was analyzed by use of FEM. In numerical analysis, the different arrangements of the edge beam were considered under the external pressure in radial direction. From the numerical results, following conclusions are obtained.

(1) The arrangement of the edge beam influences the strength of R/C shell with edge beam. Edge beam connected at the beam top is better load transfer characteristics than other connection method.

(2) At all cases, the edge beams on the meridional edge improve 0.1 to 3 times the strength of $\mathrm{R} / \mathrm{C}$ shell without edge beam.

(3) The edge beam plays an important role to avoid R/C shell failure itself. The edge beams assisted the stress redistribution after initial cracking. The effect depended on the connection method. In this analysis, L-type that had the connection of $\mathrm{R} / \mathrm{C}$ shell with edge beam was the best.

(4) Edge beam works to prevent the failure of the supporting corners. Also, it prevents the crack propagation from the edge to inner portion of $\mathrm{R} / \mathrm{C}$ shell.

\section{Acknowledgment}

This research work was done under the supports of Grants-in-Aid for Scientific Research, Japan Ministry of Education, Culture, Sports, Science and Technology (No. 26420573).

\section{References}

[1] IASS Working Group 5, "IASS Recommendation for Reinforced Concrete Shell and Folded Plates", IASS, 1979

[2] ACI Committee318, "Building Code Requirements for Structural Concrete 318-12", American Concrete Institute, 2012

[3] Hara T., "Ultimate strength of R/C cylindrical shell with edge beams", Proceedings of the International Association for Shell and Spatial Structures (IASS)Symposium 2010, Shanghai, Spatial Structures Permanent and Temporary, 202-210, November 8-12, 2010, Shanghai, China.

[4] Hinton E. and Owen D.R.J., "Finite Element Software for Plates and Shells", Pineridge Press, 1984

[5] Hinton E. "Numerical methods and software for dynamic analysis of plates and shells", Pineridge press Swansea U.K. 1988

[6] Hara T., "Dynamic analysis of $\mathrm{R} / \mathrm{C}$ cooling tower shells under earthquake loading", 5th International Symposium on NaturalDraught Cooling Towers, 283-291, 2004.

[7] Hara T. and Hadi M.N.S. "Behaviour of High Strength Concrete Columns under Eccentric Loading". Proceedings of the Tenth International Conference on Civil, Structural and Environmental Engineering Computing p16, 2005

[8] Kupfer H., Hilsdorf K.H., "Behavior of concrete under biaxial stress", ACI Journal, 66, 656-666. 1969

[9] Hara T., "Structural Behavior of R/C Shell Considering the Position of Edge Beam", $8^{\text {th }}$ International Structural and Construction Conference, Sydney, Austraria, pp299-304, 2015

About Author (s):

Takashi Hara, Professor, Dr.-Eng. PE-jp

National Institute of Technology,

Tokuyama College

Graduate from Ehime University, Japan

Dr. of Eng. Toyohashi University of

Technology, Japan

APEC Structural Engineer 